\title{
NQR Investigation of Phase Transitions in Cesium Plumbochloride
}

\section{Tovborg-Jensen, $\mathbf{N}$.}

Published in:

Journal of Chemical Physics

Link to article, DOI:

$10.1063 / 1.1670853$

Publication date:

1969

Document Version

Publisher's PDF, also known as Version of record

Link back to DTU Orbit

Citation (APA):

Tovborg-Jensen, N. (1969). NQR Investigation of Phase Transitions in Cesium Plumbochloride. Journal of Chemical Physics, 50(1), 559-560. https://doi.org/10.1063/1.1670853

\section{General rights}

Copyright and moral rights for the publications made accessible in the public portal are retained by the authors and/or other copyright owners and it is a condition of accessing publications that users recognise and abide by the legal requirements associated with these rights.

- Users may download and print one copy of any publication from the public portal for the purpose of private study or research.

- You may not further distribute the material or use it for any profit-making activity or commercial gain

- You may freely distribute the URL identifying the publication in the public portal

If you believe that this document breaches copyright please contact us providing details, and we will remove access to the work immediately and investigate your claim 
FIG. 1. Electron spin resonance spectra of VOPC in conc $\mathrm{H}_{2} \mathrm{SO}_{4}$ matrix (1.75X $10^{-3} \mathrm{~mol} / \mathrm{liter}$ ) at $77^{\circ} \mathrm{K}$ measured by JEOL p-10 type spectrometer (100 $\mathrm{kc} / \mathrm{sec}$ modulation) at $\mathbf{X}$ band. Field modulation is $3.0 \mathrm{G}$ wide for (a) and 0.7 G_for (b).

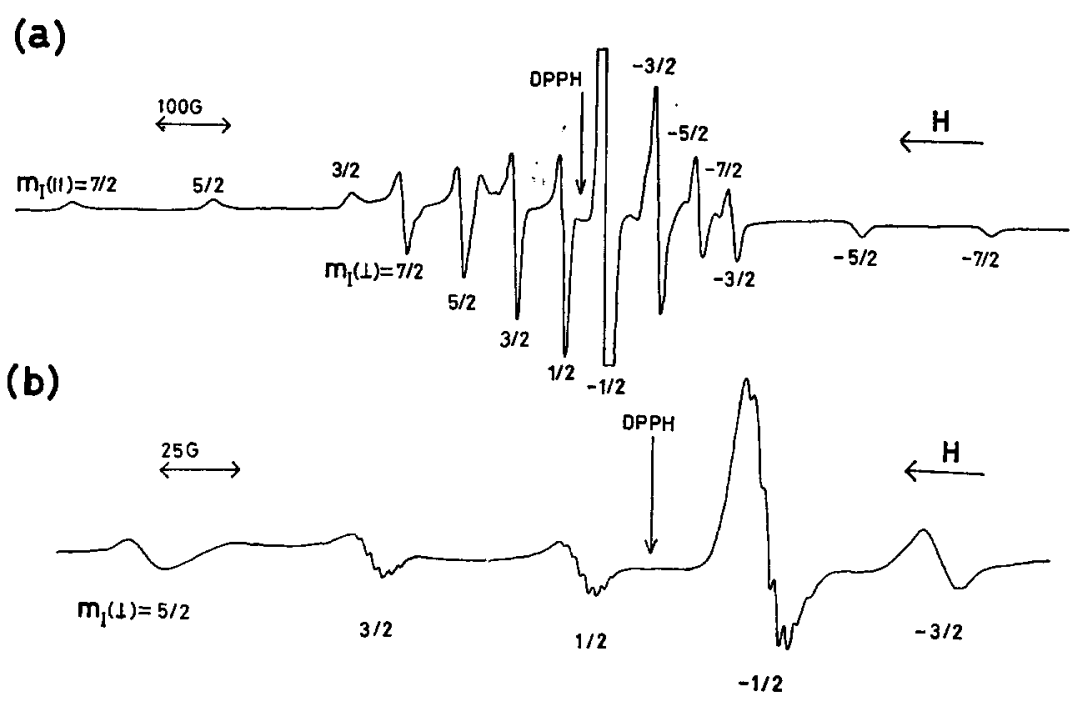

Ingram and Bennett ${ }^{1}$ on polycrystalline specimens, and more recently by Assour et al. ${ }^{2}$ on magnetically diluted VOPC samples, respectively. The latter authors, showing vanadium nuclear hyperfine (hf) structure but with the absence of the nitrogen superhyperfine (shf) lines, suggested that the unpaired electron in the vanadium $3 d_{x y}$ orbital is localized on the metal core, and that there is no in-plane $\pi$ bonding between the metal and the ligand-nitrogen atoms.

We have studied the ESR spectra of VOPC in dilute glassy matrix of conc sulfuric acid, $\alpha$-Cl-naphthalene, or of quinoline at $77^{\circ} \mathrm{K}$ and found contrary to the above authors' results that the spectra give rise to nitrogen shf structure in all solvents investigated. Thus, the unpaired electron is believed to interact with the ligand-nitrogen nuclei as in the case of vanadyl porphyrin. ${ }^{3}$

The ESR spectrum obtained with large width for the field modulation is shown in Fig. 1(a). Such a spectrum may be explained on the basis of the following spin Hamiltonian with axial symmetry:

$$
\begin{aligned}
\mathfrak{F}=\beta\left[g_{11} H_{z} S_{z}\right. & \left.+g_{\perp}\left(H_{x} S_{x}+H_{y} S_{z}\right)\right]+A_{1 \mid} I_{z} S_{z} \\
& +A_{\perp}\left(I_{x} S_{x}+I_{y} S_{y}\right) \quad\left(S=\frac{1}{2}, I=\frac{7}{2}\right),
\end{aligned}
$$

where $\beta$ is the Bohr magneton and $A$ is the vanadium nuclear hf interaction constant. After Sands ${ }^{4}$ and Bleaney, ${ }^{5}$ the spin-Hamiltonian parameters were calculated as

$$
\begin{gathered}
g_{\| \mid}=1.968 \pm 0.002, \quad g_{\perp}=1.987 \pm 0.001 \\
A_{\| 1}=-(161.2 \pm 2.0) \times 10^{-4} \mathrm{~cm}^{-1} \\
A_{\perp}=-(57.3 \pm 1.0) \times 10^{-4} \mathrm{~cm}^{-1}
\end{gathered}
$$

When a small width for the field modulation such as $0.7 \mathrm{G}$ was applied, some of the perpendicular hf lines $\left(m_{I}=\frac{3}{2}, \frac{1}{2},-\frac{1}{2}\right)$ were found to split into at least seven lines spaced with separations of 2.5-3.0 G [Fig. 1(b)]. Such splittings were not observed, however, on the other perpendicular lines $\left(m_{I}=\frac{7}{2}, \frac{5}{2},-\frac{3}{2},-\frac{5}{2},-\frac{7}{2}\right)$ nor on any parallel lines. Splitting of this sort may be interpreted qualitatively if the unpaired electron of the vanadium interacts with the ligand-nitrogen nuclei.

The nitrogen shf structure can be explained by adding the following term to Eq. (1)

$$
\sum\left[A_{\| 1}{ }^{\mathrm{N}} S_{z} I_{z}{ }^{\mathrm{N}}+A_{\perp}{ }^{\mathrm{N}}\left(S_{x} I_{x}^{\mathrm{N}}+S_{y} I_{y}^{\mathrm{N}}\right)\right],
$$

where $I^{\mathrm{N}}$ refers to nitrogen nuclear spin $(I=1)$ and $A^{\mathrm{N}}$ to nitrogen shf constant. Accordingly, if the four nitrogen ligands are magnetically equivalent, nine shf lines should be observed with relative intensities of

$$
1: 4: 10: 16: 19: 16: 10: 4: 1 \text {. }
$$

The observed shf structure is consistent with this expectation, if two weakest lines are assumed to be smeared out. On the other hand, it is not obvious why not all the vanadium hf lines give rise to nitrogen shf structure.

The spin density around the nitrogen ligands of VOPC is expected to arise from the delocalization of in-plane $\pi$ bonding or from the configuration interaction of such orbital as in-plane $\sigma$ bonding. ${ }^{3}$ To discuss the bonding scheme along the line accurate data for $A_{\| 1}{ }^{\mathrm{N}}$ are at least required. Unfortunately we were unable to detect $A_{\| 1}$.

1 D. J. E. Ingram and J. E. Bennett, J. Chem. Phys. 22, 1136 (1954); Discussions Faraday Soc. 19, 140 (1955).

${ }^{2}$ J. M. Assour, J. Goldmacher, and S. E. Harrison, J. Chem. Phys. 43, 159 (1965).

'D. Kivelson and S. K. Lee, J. Chem. Phys. 41, 1896 (1964).

'R. H. Sands, Phys. Rev. 99, 1222 (1955).

s G. Bleaney, Phil. Mag. 42, 441 (1951).

\section{NQR Investigation of Phase Transitions in Cesium Plumbochloride}

\author{
N. TOVBORG-JENSEN \\ Electrotechnical Laboratory, Technical University of \\ Denmark, Lyngby \\ (Received 14 August 1968)
}

As has been demonstrated by Mфller, ${ }^{1-2}$ cesium plumbochloride $\left(\mathrm{CsPbCl}_{3}\right)$ has the cubic perovskite 


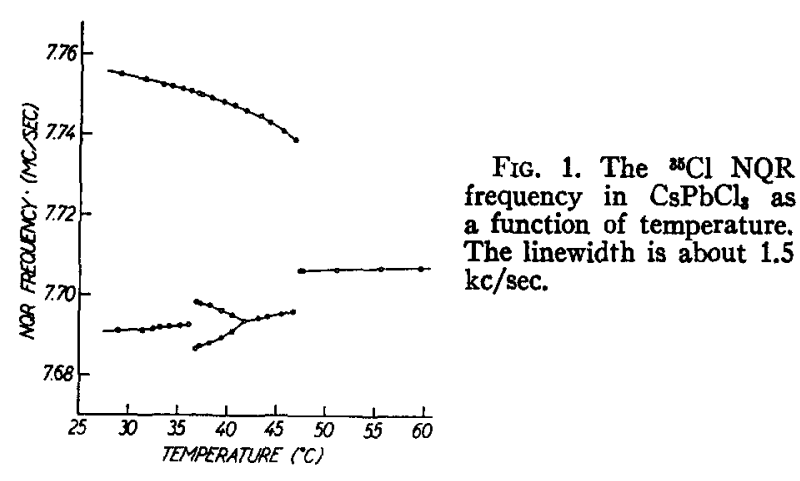

structure above $47^{\circ} \mathrm{C}$ and a slightly distorted tetragonal structure below this temperature. Furthermore it is suggested ${ }^{1}$ that the cesium atoms and the chlorine atoms are displaced from the ideal positions expected for the perovskite structure. $\mathrm{A} \mathrm{Cl}^{35}$ pure quadrupole resonance experiment has been carried out on $\mathrm{CsPbCl}_{3}$ powder to get further information on this structure, the results being shown in Fig. 1.

The NQR experiment indicates clearly that the phase transition at $47^{\circ} \mathrm{C}^{1}$ is a first-order transition. At $42^{\circ} \mathrm{C}$ the low-frequency line, the intensity of which is about twice as high as that of the other line, splits into two lines; this indicates a phase transition of the second order which has not been observed previously. At $37^{\circ} \mathrm{C}$ the splitting of the low-frequency line disappears through a first-order transition. No hysteresis has been detected in any of the transitions.

Above $47^{\circ} \mathrm{C}$ all chlorine atoms are placed at the same field gradient corresponding to crystallographically identical positions. Between $47^{\circ}$ and $42^{\circ} \mathrm{C}$ the crystal is tetragonal ${ }^{1}$ with two crystallographically nonidentical chlorine positions; the low-intensity line originates in the chlorine atoms placed at the fourfold axes and the high-intensity one in the chlorine atoms placed at the twofold axes. As the main contribution to the field gradient originates in the $\mathrm{Pb}$ ions, the relative positions of the two lines in the diagram are the opposite of what might be expected for the simplest possible transition from the cubic phase to the tetragonal one (i.e., an elongation of the $c$ axis and a simultaneous contraction of the two axes perpendicular to the $c$ axis). This indicates that some rearrangement of the chlorine atoms must take place during the phase transition at $47^{\circ} \mathrm{C} \cdot{ }^{1}$ Between $42^{\circ}$ and $37^{\circ} \mathrm{C}$, three lines of approximately the same intensity are observed corresponding to three different chlorine positions. It should be noted that the two transitions at $42^{\circ}$ and $37^{\circ} \mathrm{C}$ take place in such a way that the chlorine atoms placed at the fourfold axes obviously are unaffected.

Taking into account the two nearest $\mathrm{Pb}^{2+}$ ions, the four nearest $\mathrm{Cs}^{+}$ions, and the eight nearest $\mathrm{Cl}^{-}$ions, the experimentally determined Sternheimer antishielding factor is -23 . The experiment thus indicates that the quadrupole coupling is entirely ionic.

1 C. K. Mфller, Kgl. Danske Videnskab. Selskab Mat. Fys. Medd. 32, 1 (1959).

C. K. Møller, Nature 182, 981 (1957).

\section{Raman Spectra from Dilute Solutions of $\mathrm{HDO}$ in $\mathrm{D}_{2} \mathrm{O}$}

\author{
G. E. WALRAFEN \\ Bell Telephone Laboratories, Incorporated, \\ Murray Hill, New Jersey 07974 \\ (Received 23 July 1968)
}

Raman spectra from a $6.2 \mathrm{M}$ (11 mole\%) solution of $\mathrm{D}_{2} \mathrm{O}$ in $\mathrm{H}_{2} \mathrm{O}$ were reported recently. ${ }^{1}$ The OD stretching contour from the $6.2 \mathrm{M}$ solution was observed to be markedly asymmetric at $25^{\circ} \mathrm{C}$. A high-frequency shoulder was evident near $2660 \pm 20 \mathrm{~cm}^{-1}$ which was separated by an inflection from the contour maximum at $2515 \pm 5 \mathrm{~cm}^{-1}$. Inflections and shoulders have also been observed in the OD stretching contour from a $3.1 \mathrm{M}$ (6 mole\%) solution of $\mathrm{D}_{2} \mathrm{O}$ in $\mathrm{H}_{2} \mathrm{O}$ and in the $\mathrm{OH}$ stretching contours from $6.5 \mathrm{M}(12 \mathrm{~mole} \%)$ and $2.8 \mathrm{M}$ ( 5 mole\%) solutions of $\mathrm{H}_{2} \mathrm{O}$ in $\mathrm{D}_{2} \mathrm{O}^{2}$ Some evidence for weak components arising from intermolecular coupling between $\mathrm{HDO}$ vibrations was obtained, however, and thus it seemed desirable to investigate solutions more dilute than 5 mole\%. Accordingly, Raman spectra from a $0.5_{6} \mathrm{M}$ (1 mole\%) solution of $\mathrm{H}_{2} \mathrm{O}$ in $\mathrm{D}_{2} \mathrm{O}$ were obtained in this work. ${ }^{3}$

Photoelectric Raman spectra from the $0.5_{G} M$ or 1 mole\% solution were obtained in the $\mathrm{OH}$ stretching region with a Spectrophysics 140 argon-ion-laser having maximum intensity approaching $1 \mathrm{~W}$ at $4880 \AA$. A Cary Model 81 Raman spectrophotometer modified to utilize an ITT FW 130 (S-20) phototube was used

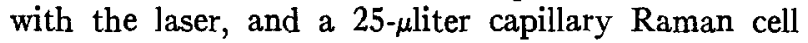
was employed with the Cary image slicer. A typical spectrum is shown in Fig. 1.

Examination of Fig. 1 (upper section) indicates pronounced asymmetry in the $\mathrm{OH}$ stretching contour from the dilute HDO solution. A shoulder is evident near $3630 \pm 20 \mathrm{~cm}^{-1}$, and it is separated from the contour maximum by an inflection near $3600 \pm 20 \mathrm{~cm}^{-1}$.

Detailed analysis of the $\mathrm{OH}$ contour was accomplished by determining the base line from extrapolation of curvatures above $3700 \mathrm{~cm}^{-1}$ and below $3100 \mathrm{~cm}^{-1}$ (see the dashed line in Fig. 1). (The slope and curvature resulted from proximity to the extremely intense OD stretching contour, and from other sources, e.g., from the capillary cell, and from the required high amplification.) The spectral contour was then transferred to a horizontal base line (lower section of Fig. 1), where a pronounced high-frequency shoulder is evident. The quantity $|d I / d \bar{\nu}|$ from the transferred curve, the absolute value of the derivative of contour intensity with respect to frequency shift in $\mathrm{cm}^{-1}$, was found to be minimal near $3600 \pm 20 \mathrm{~cm}^{-1}$, and zero near $3435 \pm 10$ $\mathrm{cm}^{-1}$. Analog decomposition of the transferred curve by means of the duPont 310 curve Resolver also revealed two major Gaussian components near 3435 and $3628 \mathrm{~cm}^{-1}$, indicated in Fig. 1 by peak height and peak width.

The shape of the $\mathrm{OH}$ stretching contour indicated 